\title{
How still is still? Exploring human standstill for artistic applications
}

\author{
Alexander Refsum Jensenius* \\ Department of Musicology, \\ University of Oslo, \\ PB 1017 Blindern, 0315 Oslo, Norway \\ E-mail: a.r.jensenius@imv.uio.no \\ *Corresponding author
}

\section{Kari Anne Vadstensvik Bjerkestrand}

BodyMindFlow

Liaveien 10, 1450 Nesoddtangen, Norway

E-mail: ka@bodymindflow.com

\section{Victoria Johnson}

Norwegian Academy of Music,

Arne Nordheim Centre,

PB 5190 Majorstuen, 0302 Oslo, Norway

E-mail: post@victoriajohnson.no

\begin{abstract}
In this paper, we present the results of a series of observation studies of the three team members standing still for ten minutes at a time. The aim has been to understand more about people's ability to stand still, and to develop a heightened sensitivity for micromovements and how they might be used in music and dance performances. The quantity of motion, calculated from motion capture data using a head marker, was remarkably similar for each person who stood still. The 'best' results - that is, the least movement - were obtained when the subject set his/her feet at the width of the shoulders, locked the knees, and kept the eyes open. No correlation was found between quantity of motion and type of mental coping strategy, though we remain convinced that mental strategies influence the experience of standing still. These findings will be used to inform the development of a stage performance focused on micromovements.
\end{abstract}

Keywords: micromovement; standstill; dance; music; motion capture.

Reference to this paper should be made as follows: Jensenius, A.R., Bjerkestrand, K.A.V. and Johnson, V. (xxxx) 'How still is still? Exploring human standstill for artistic applications', Int. J. Arts and Technology, Vol. x, No. $\mathrm{x}, \mathrm{pp} . \mathrm{xxx}-\mathrm{xxx}$. 
Biographical notes: Alexander Refsum Jensenius is a music researcher and research musician working in the fields of embodied music cognition and new interfaces for musical expression at the University of Oslo and at the Norwegian Academy of Music.

Kari Anne Vadstensvik Bjerkestrand is a freelance dancer and choreographer working on projects where dance and music are closely connected. She also teaches her own method BodyMindFlow, which addresses the fields of leadership, creativity and consciousness.

Victoria Johnson is an electric violinist and research musician at the Norwegian Academy of Music. She has established herself internationally as a soloist, chamber musician and improviser in the fields of contemporary, improvised, experimental and cross-disciplinary music and art. She also teaches at the Barratt Due Institute of Music.

This paper is a revised and expanded version of a paper entitled 'Exploring micromovements with motion capture and sonification' presented at Second International Conference, ArtsIT 2011, Esbjerg, Denmark, December 2011.

\section{Introduction}

Human beings cannot stand absolutely still. Even when we try our hardest, we still must breathe and make postural adjustments that lead to tiny body movements. As this paper documents, such micromovements typically happen at a scale of less than ten millimetres per second $(\mathrm{mm} / \mathrm{s})$. Though micromovements are therefore quite small, we can easily feel them, and others can see them as well. In fact, the project members (and study subjects) believe that micromovements are crucial to conveying a range of expressive features and are, as such, central to most human communication. Micromovements are thus an important part of most music and dance performances as well, but they have yet to be properly exploited in and of themselves in artistic performance. Our goal with the present project, titled Sverm (the Norwegian word for swarm), is to create an entire staged music/dance performance centred upon micromovements. Parallel to this particular artistic endeavour, the project team is also interested in the scientific investigation of micromovements, as well as the ultimate development of a systematic approach to studying and working with micromovements in music and dance.

Our interests in, and perspectives upon, the topic of micromovements are based on our backgrounds in music (first and third authors) and dance (second author). Body movement is at the forefront of both music and dance, although in different ways: the body movements of a musician are mainly sound producing, while the movements of a dancer are (often) sound accompanying (Jensenius et al., 2010). This traditional movement-related distinction between the musician and the dancer is currently being challenged, interestingly, through the increasing use of various types of motion capture technologies that allow a dancer to create sound in realtime while moving (Skogstad et al., 2010), or allow a musician to move more freely while playing (Jensenius and Johnson, 2010). 
In a pilot project leading up to the current project, the team undertook a systematic study of the micromovements that could be observed when a person stood still, with the feet flat on the floor (Jensenius and Bjerkestrand, 2012). The task, specifically, was to stand still for ten minutes at a time; after which we discussed our experiences. We then compared these subjective accounts to data from motion capture recordings of the session, which inevitably revealed that our micromovements were much larger than we had anticipated. We were thus led to embark upon a more in-depth study of the micromovements that are observable when one stand still, which is, in turn, the focus of this paper.

The research questions we have set out to answer are as follows:

- How still is it possible to stand? How stable is the 'level of standstill' for one person? Does the level of standstill change at different times of the day, or across days, months, or years?

- Are there any physical or mental strategies that might alter or improve one's level of standstill?

- How does listening to sound or music influence standstill?

- What types of temporal and spatial patterns can be found in standstill?

- Is there a relationship between the subjective experience of a person who is standing still and the measurable level of standstill?

- How might standstill be used in an artistic setting?

We begin this paper with a definition of standstill, followed by a brief survey of related literature on the topic (Section 2). Then we present the methods used in the observation study (Section 3), before presenting and discussing the study results (Sections 4 and 5).

\section{Standstill}

\subsection{Definition}

Given that this is new territory for the present team, we have spent a great deal of time trying to clarify the relevant terminology. In the beginning of the project we used the word stillness to describe the act of standing still; this word also describes the phenomenon in medical literature (Mulholland, 1995). We soon discovered, however, that 'stillness' is clearly ambiguous in a musical context, since the word does not differentiate between the acts of standing physically still and of being silent - that is, making no sound. The same is the case for the term quiet standing, which is used in biomechanics and physiotherapy literature (Winter, 1995). Because we are working on both music and dance, we needed a word that describes the act of standing physically still, regardless of whether the person makes sound or not.

There are several English words that describe the act of not moving, including immobile, inactive, motionless and stationary. To us, however, these words suggested an inability to move, while we were interested in evoking the act of voluntarily not moving. Our solution, then, was to use the word standstill. This word may have a negative connotation to some, as it is often used to describe a traffic jam or a machine 
breakdown. Yet we find it to be the most precise way to describe what we have actually been doing: standing still.

\subsection{Background}

There has been relatively little interest in standstill and micromovements in the fields of dance and music. This may be because standstill is often regarded simply as the 'fill' between actions and gestures, in the same way that musicians and musicologists often tend to focus more on sound than on silence. But silence (and microsounds) can be very powerful in music, as perhaps most famously documented in several pieces by Cage (1961), and we believe that standstill and micromovements can be equally interesting to work from and with, in both music and dance.

Standstill and micromovements have in fact been studied in several other fields, including:

- Psychology: The seminal work on microexpressions by Ekman and Friesen (1969) showed how facial micromovements can tell a lot about peoples' feelings, and can, for example, be used to help determine when someone is lying. Similarly, research on micromovements of the eyes - such as microsaccades, drifts and tremors - has shown that our eyes are always in motion (Martinez-Conde and Macknik, 2007), and that microsaccades in particular are related to our mental visualisations (Laeng and Teodorescu, 2002).

- Biomechanics: The biomechanical nature of standstill is often studied as a case of the 'human pendulum', which sways in a semi-random pattern as adjustments take place throughout the body (Collins and De Luca, 1994; Winter et al., 1998; Loram and Lakie, 2002). Many of these studies focus on explaining the biomechanical nature of the swaying movement observed in standstill, using force plates to examine feet and leg activity.

- Rehabilitation: Different types of slow-movement practice or standstill can also be found in traditions like Feldenkrais (1972), the Alexander technique (Barlow, 1975), release technique (Johnson, 1995), and kinetic awareness (Saltonstall, 1988). These tools accommodate a deeper awareness or recovery from misalignments or injuries in the body.

- Chronobiology: This research field focuses on understanding the temporal and rhythmic unfolding of various life processes, including those of plants, animals and human beings (Klein, 2007). The periods of such cycles vary greatly, from the level of molecular movement within our bodies, to breathing and pulse cycles every few seconds, to 24-hour circadian sleep/wake cycles and the yearly cycles of nature's seasons.

- Movement practices: Our project is to some extent inspired by slow-movement traditions like Tai chi chuan, which was explored by the second author in the piece 10:50-11:00 (Jacobsson and Bjerkestrand, 2005).

- Dance: The concepts of standstill and micromovement have been discussed to some extent in dance literature (Kozel, 2011), but we have not been able to identify much systematic work regarding the use of micromovements themselves 
in performance. The closest parallel may be the very slow, controlled movement of the Japanese Butoh dance (Kurihara, 2000). We will continue to investigate how this tradition and other might influence our own work in the future.

\section{Observation studies of standstill}

The observation studies of standstill that we report on here are based on the same method as used in our previous study (Jensenius and Bjerkestrand, 2012). The aim has been to learn more about our own experiences of standing still, and to test whether different physical and mental strategies might change the measurable level of standstill. We have recorded a total of forty sessions over a period of four weeks, typically one to three recordings per meting day. All of the recordings lasted for ten minutes, except for one which lasted 15 minutes. Twenty-five of the recordings were of standstill, and 15 were based on doing various types of micromovement exercises. In this paper, we will focus on the former.

\subsection{Experimental tasks}

We have tested a number of different physical and mental strategies for standing still, which can briefly be summarised as follows:

a physical standstill (recordings 1, 3, 12, 17, 19, 24)

b mental strategies (recordings 2, 4, 5, 14, 29, 32, 33)

c foot positions (recordings 9, 10, 36, 37, 39)

d eyes open (recordings 15, 22, 35, 38, 39)

e listening (recordings $11,13,16,18$ ).

In task (a), we focused on standing as physically still as possible. Task (b) dealt with exploring different types of mental strategies, ranging from simply trying to be as calm as possible to carry out active exercises such as counting numbers. In task (c), we explored how different foot positions altered the level of standstill, and in task (d), whether having open or closed eyes would influence the results. In task (e), we were interested in whether listening to sound or music would influence the results.

\subsection{Data collection}

All standstill sessions were carried out in the fourMs motion capture laboratories at the University of Oslo and were recorded using an infrared marker-based motion capture system from Qualisys (9 Oqus 300 cameras). In our previous study (Jensenius and Bjerkestrand, 2012), we had multiple markers placed on various joints on the body but mainly focused our analysis on a marker placed on the neck. This time, we decided to use only one marker on the head of each person (see Figure 1), which is the outmost part of the 'swinging body'. Using only one marker per person simplified the setup, both practically and conceptually, and still provided sufficient amounts of data for analysis. 
The three-dimensional position of each marker was captured with a sampling rate of $20 \mathrm{~Hz}$, which was more than fast enough for the type of motion that we were measuring. The motion capture system was calibrated before each recording session, to ensure the highest possible accuracy and precision of the data. We have previously shown that the spatial noise level of the system, recorded as a ratio between the positional drift of a static marker and that of a marker placed on the head of a person standing still, is approximately 1:14 (Jensenius et al., 2012). As such, we are confident that the recorded micromovements are by the subjects, and not the result of noise within the system itself.

Figure 1 Setup for the standstill sessions

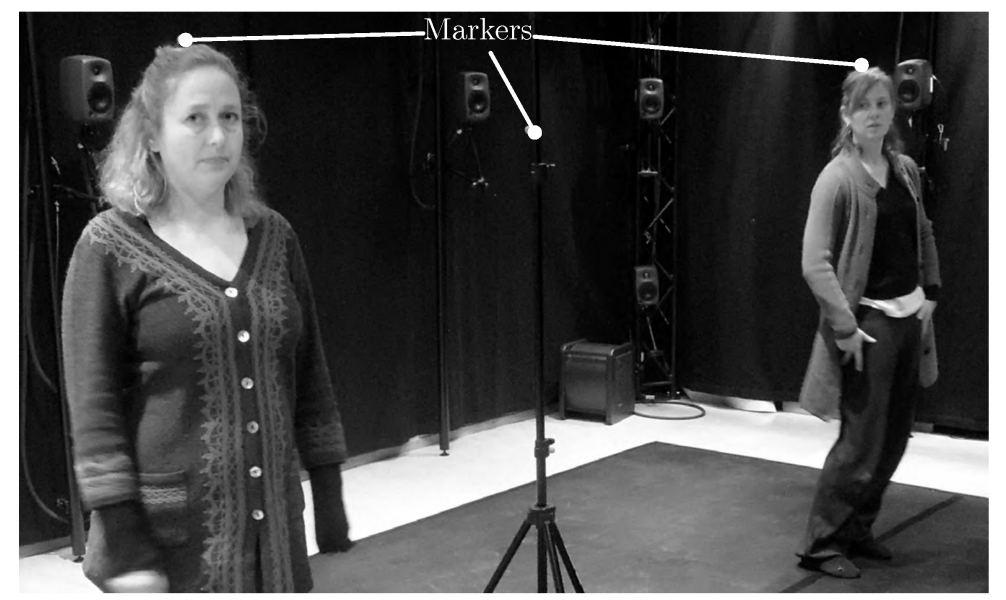

Note: Each subject had a reflective marker placed on the head, and one static marker was recorded from a standing pole as a reference.

Video and audio were recorded together with the motion capture data as a reference to assist analysis. We also took notes of our subjective experiences after each recording session. These notes, together with analysis of the motion capture data carried out in Matlab using the MoCap toolbox (Toiviainen and Burger, 2010), form the basis for our analysis of the material.

\subsection{Quantifying motion}

To give an impression of what the data looks like, Figure 2 shows a plot of the $X$ (sideways), Y (front to back), and Z (height) axes of a recording. In fact, this recording features the least movement to date, but we see that there is still a lot of micromovement in all three axes and at different spatial and temporal scales.

It is one thing to register our subjective impressions of how much we move or how much we can see another person moving. It is quite another, however, to determine how much movement we can actually measure, and how we might quantify it. In this paper we will calculate the quantity of motion (QoM) using the following equation:

$$
Q \circ M=\frac{1}{T} \sum_{n=2}^{N}\|\mathbf{p}(n)-\mathbf{p}(n-1)\|
$$


where $\mathbf{p}$ is the $3 \mathrm{D}$ position vector of a marker, $N$ is the total number of samples and $T$ is the total duration of the recording.

In plain English, the equation indicates that the QoM can be calculated by summing up all of the differences of consecutive samples for the magnitude of the position vector - that is, the first derivative of the position. This sum, which is sometimes called the cumulative distance travelled, is then divided by the duration of the recording. The resultant QoM is measured in millimetres per second $(\mathrm{mm} / \mathrm{s})$ and is the unit that will be used in the rest of this paper.

Figure 2 Plots of the X (sideways), Y (front to back) and Z (height) axes of the normalised position of a head marker, using the recording with the least movement in our dataset (see online version for colours)
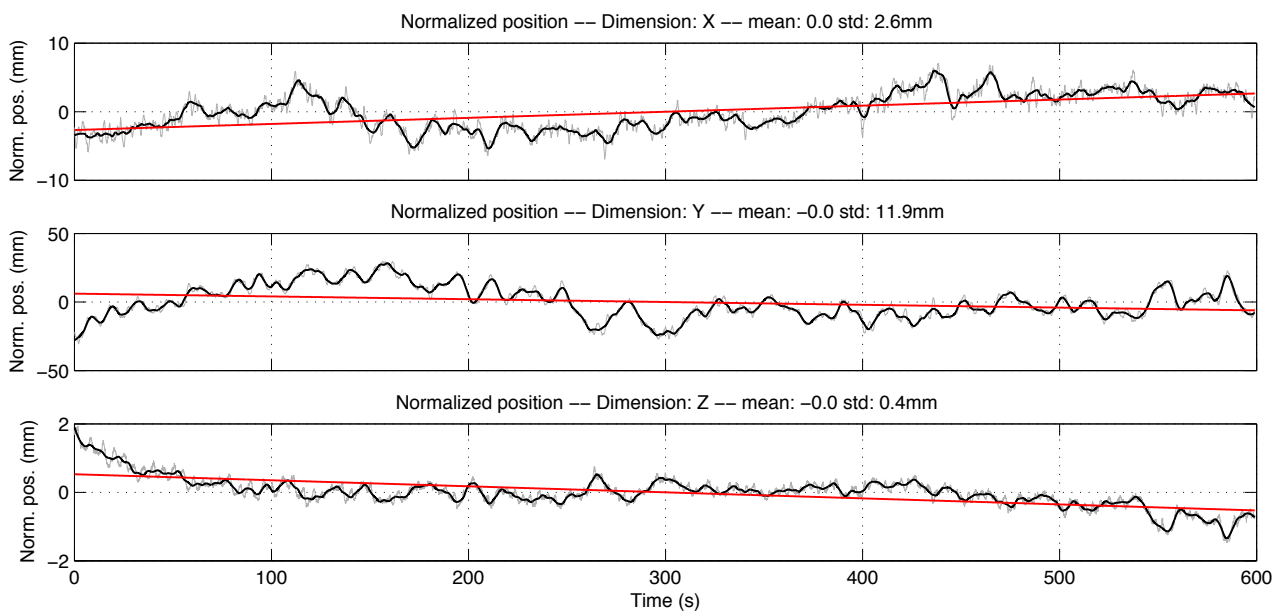

Note: The grey line is the raw data; the black line results from a ten-second smoothing filter; and the red line shows the linear regression (the trend) of the dataset.

\section{Results}

Table 1 presents a summary of the QoM values for all of the team's standstill recordings. The results in this table represent the point of departure for the discussion in the following sections.

\subsection{How still?}

Our subjective experience of the sessions can be easily summarised: we are not able to stand absolutely still. In all of our recordings we saw right away how shifting weight between the legs, swaying, breathing, swallowing, and so on set our bodies in motion. These micromovements are also easy to see when we look at plots of the recordings, like the ones in Figure 2. The list of QoM values in Table 1 shows that our heads were moving at approximately $4-9 \mathrm{~mm} / \mathrm{s}$ on average. 
One observation that can be made from the data in Table 1 is that the average values (both mean and median) are quite similar for all three of the team members, even though we have different professional backgrounds (two music researchers/musicians and one dancer), different heights $(185 \mathrm{~cm}, 175 \mathrm{~cm}, 165 \mathrm{~cm})$, and different genders (one male, two females). Also, even though the average values for the three of us differ slightly, the ranges between our lowest and highest QoM values are remarkably even, with all three of us sharing the maximum QoM of around $9 \mathrm{~mm} / \mathrm{s}$. It is interesting that the range of the values was not larger, particularly taking into account that the recordings were done over the course of four weeks, at different times of the day, and with different numbers of recordings per day.

Table 1 Summary of QoM for all standstill recordings (in $\mathrm{mm} / \mathrm{s}$ ) for each of the authors (the initials of the authors are used as column names: ARJ, KAVB, VJ)

\begin{tabular}{|c|c|c|c|c|}
\hline Session \# & $A R J$ & $K A V B$ & $V J$ & Physical/mental task \\
\hline 1 & 5.1 & 7.0 & 6.6 & Physical standstill \\
\hline 2 & 6.1 & 7.4 & 5.9 & Mental: calmness \\
\hline 3 & 5.1 & 7.2 & 6.4 & Physical standstill \\
\hline 4 & 4.8 & 7.0 & 6.1 & Mental: calmness \\
\hline 5 & 5.6 & 7.0 & 6.2 & Mental: emotional peace \\
\hline 9 & 7.3 & 9.0 & 8.1 & 1st position feet \\
\hline 10 & 6.7 & 8.7 & 8.5 & 1st position feet, folded hands \\
\hline 11 & 4.9 & 7.3 & 6.5 & Listening: clicks \\
\hline 12 & 4.4 & 6.9 & 5.9 & Physical standstill \\
\hline 13 & 4.9 & 7.5 & 5.9 & Listening: rain \\
\hline 14 & 4.9 & 7.3 & 5.9 & Mental: calmness \\
\hline 15 & 3.8 & 6.0 & 5.2 & Eyes open \\
\hline 16 & 4.8 & 7.2 & 8.6 & Listening: music \\
\hline 17 & 5.1 & 7.8 & 5.8 & Physical standstill (15 min) \\
\hline 18 & 4.8 & 7.7 & 5.8 & Listening: ambience \\
\hline 19 & 4.6 & 7.1 & 5.8 & Physical standstill \\
\hline 22 & 5.2 & 6.0 & 5.2 & Eyes open \\
\hline 24 & 4.6 & 7.2 & 6.0 & Physical standstill \\
\hline 29 & 4.9 & 7.2 & 5.9 & Mental: calmness \\
\hline 32 & 5.0 & 7.9 & 6.0 & Mental: counting numbers \\
\hline 33 & 4.3 & 7.6 & 6.2 & Mental: calmness \\
\hline 35 & 4.2 & 6.1 & 5.6 & Eyes open \\
\hline 36 & 5.1 & 8.0 & 8.9 & 4 th position feet \\
\hline 37 & 8.7 & 8.7 & 8.2 & 4th parallel feet \\
\hline 38 & 4.8 & 5.0 & 5.4 & Locked knees. eyes open \\
\hline Mean & 5.2 & 7.3 & 6.4 & \\
\hline Median & 4.9 & 7.2 & 6.0 & \\
\hline Std & 1.1 & 0.9 & 1.1 & \\
\hline Min & 3.8 & 5.0 & 5.2 & \\
\hline Max & 8.7 & 9.0 & 8.9 & \\
\hline
\end{tabular}

Note: The numbers in italics in the table indicate the minimum and maximum values for each person.

When we compared the measured QoM values to the subjective experiences of our own standstill levels (written down after each recording), we found correlations in some cases, but not all. It appears that we are quite good at noticing when we are doing 
'poorly', - that is, moving more than usual - but less accurate at noting when we are actually standing physically still. The general impression, though, is that the variability of the measured QoM is much smaller than we would have expected, especially compared to the quite large perceived differences among the sessions. For example, there were only marginal differences in the measured QoM between a day when one subject felt she was standing exceptionally still and another day when she was feeling very tired and unbalanced. As such, it appears that the measurable level of standstill is fairly stable for one person, regardless of his or her general well-being on the day, the time of the day, and so on. What seems to matter more is the physical or mental strategy chosen for the standstill session - for example, whether one's eyes were open or closed, or how one's feet were positioned.

\subsection{Open or closed eyes}

During most of the recordings we stood with eyes closed all of the time. In general, we all felt that this was the most comfortable way to stand still, and that it helped us to focus on our own experiences. We did, however, carry out four sessions with eyes open (recordings 15, 22, 35, 38). Interestingly, these four recordings, with only one exception, had the lowest QoM values in the entire dataset (mean values: ARJ $=4.5 \mathrm{~mm} / \mathrm{s}$ $\mathrm{KAVB}=5.8 \mathrm{~mm} / \mathrm{s} \mathrm{VJ}=5.3 \mathrm{~mm} / \mathrm{s}$ ). Presumably, then, open eyes contributed to our ability to stabilise ourselves. Besides being an attractive asset in the pursuit of standing perfectly still, then, working with open (versus closed) eyes also has an important communicative side that will be interesting to explore further when we develop our performance.

\subsection{Foot positions}

For most of the recordings, we chose to stand with our feet placed shoulder-width apart, and with our arms hanging down [Figure 3(a)]. We never planned to stand this way, but it felt like the 'normal' way to stand still for ten minutes. To understand more about how the position of the feet would change our standstill, however, we decided to explore some other foot positions as well. First we tried standing in what is called the first position in classical ballet - that is, with heels together and feet facing the opposite way [Figure 3(d)]. This position felt awkward and was challenging to maintain for ARJ and VJ, while KAVB, the classically trained dancer, thought it was comfortable. Correspondingly, this position resulted in some of the poorest QoM values of the entire dataset, for all of us (ARJ $=7.3 \mathrm{~mm} / \mathrm{s} \mathrm{KAVB}=9.0 \mathrm{~mm} / \mathrm{s} \mathrm{VJ}=8.1 \mathrm{~mm} / \mathrm{s}$ ). We can safely conclude, then, that this position was less stable than standing with the feet placed at shoulder width. We achieved similar results when we stood in first position with our feet and closed our hands in front of our bodies [Figure 3(e)]. While the results were in fact slightly better than the previous recording, despite our expectations otherwise $(\mathrm{ARJ}=6.7 \mathrm{~mm} / \mathrm{s} \mathrm{KAVB}=8.7 \mathrm{~mm} / \mathrm{s} \mathrm{VJ}=8.5 \mathrm{~mm} / \mathrm{s})$, this may be explained by natural variance.

To test the effects of placing our feet further apart and aligning them differently, we also tried standing in the fourth and fourth parallel positions [Figures 3(f) and $3(\mathrm{~g})]$. Both of these positions felt physically uncomfortable to all three of us, and these two sessions were the only ones during which we were all uncertain as to whether 
we would manage to stand through the entire ten-minute recording. As expected, the QoM values were among the highest obtained in the study $(A R J=5.1 / 8.7 \mathrm{~mm} / \mathrm{s}$ $\mathrm{KAVB}=8.0 / 8.7 \mathrm{~mm} / \mathrm{s} \mathrm{VJ}=8.9 / 8.2 \mathrm{~mm} / \mathrm{s})$. The only exception was that ARJ had a QoM value close to his mean $(5.1 \mathrm{~mm} / \mathrm{s})$ when standing in the fourth position, but his subjective experience here was that he had to work very hard to maintain the position for such a long period of time. Another observation that can be made from these two recordings of shifted foot positions was that our swaying patterns changed from being more or less evenly distributed in space (see Section 4.7) to being shifted to either the left or the right side (Figure 4).

Figure 3 Examples of the different positions tested, (a) normal (b) locked knees (c) open knees (d) first position (e) first position and hands together (f) fourth position (g) fourth parallel

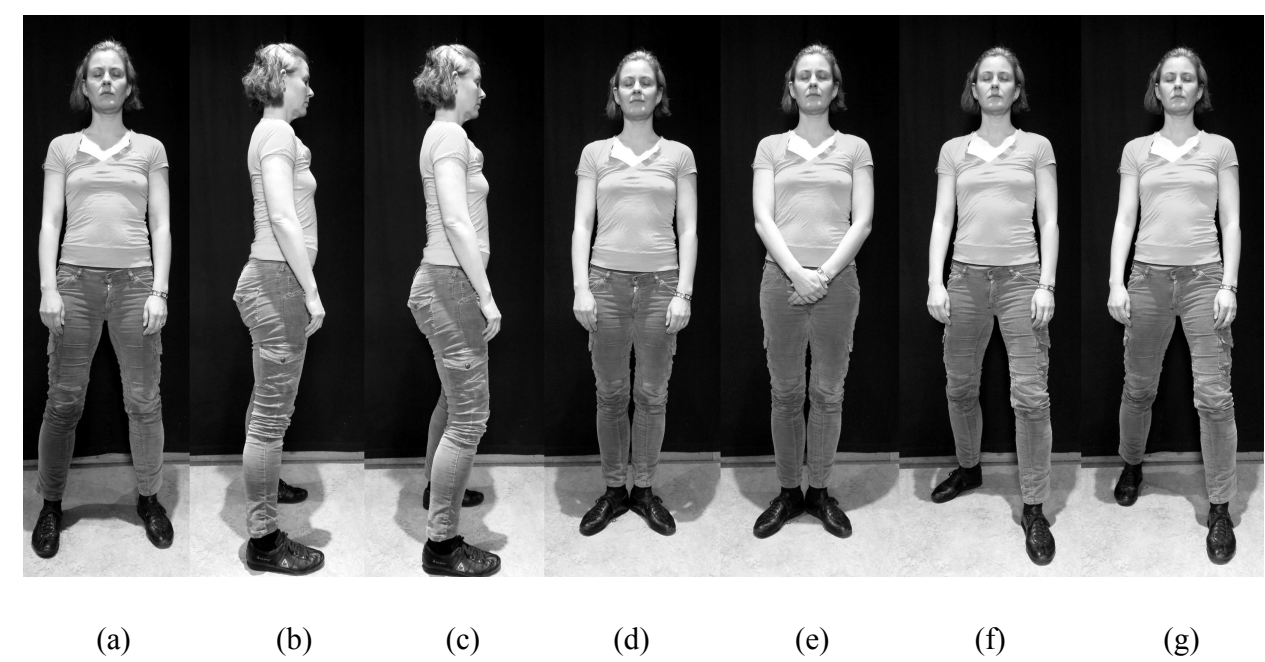

Figure 4 Standing with the feet in fourth position (\# 36) or fourth parallel (\# 37) resulted in slightly tilted $\mathrm{XY}$ movement patterns (seen from above, nose direction upward)
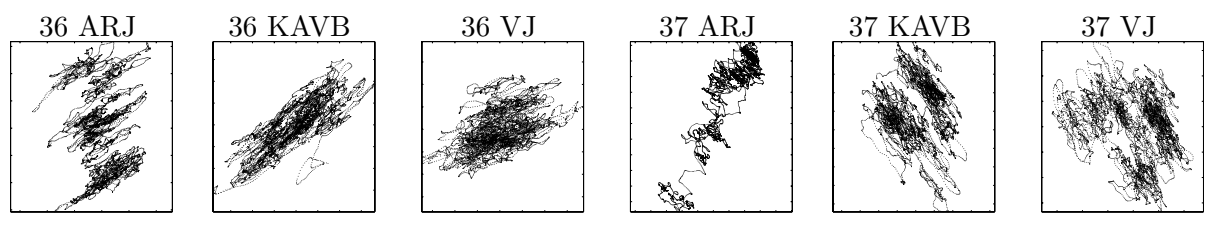

\subsection{Open or locked knees}

One aspect that became apparent to us quite late in the process was that ARJ had stood with locked knees in most recordings, while KAVB and VJ had stood with open knees [as illustrated in Figures 3(b) and 3(c)]. This corresponded well with the finding that the mean QoM of ARJ was slightly lower than those of the other two subjects. To check whether this characteristic actually had an impact on the numbers, we did one recording (\#38) in which all three of us stood with locked knees. This resulted in QoM values for 
$\operatorname{KAVB}(5.0 \mathrm{~mm} / \mathrm{s})$ and VJ $(5.4 \mathrm{~mm} / \mathrm{s})$ that were much lower than their averages, and closer to the average QoM values of ARJ. Although this finding needs to be verified in future studies, it appears that locking the knees has a clear impact on the ability to stand still. However, while locking the knees improves one's ability to stand still, it also makes it more difficult to follow micromovements in the body in a controlled manner. So if the aim is to be able to work with the micromovements, it is better to stand with open knees. Nevertheless, this knowledge about the importance of opening or locking the knees might be used as a means of intentionally transitioning between different levels of standstill in an artistic context.

\subsection{Passive or active listening}

Since sound will be an important part of our eventual performance, we were curious about whether listening to sound (musical and non-musical) would impact our standstill results. We were not able to fully investigate this question at this stage, but we carried out a few recordings where we listened to (semi-)periodic electronic sounds (\#11 and $\# 13$ ), a ten-minute electroacoustic music piece with a complex rhythmic pattern (\#16) and the background sound in the lab (\#18). While all of us felt that the experience of standing still changed drastically when were focused upon listening actively, we were not able to find any impact on the QoM values for these recordings. The only exception to this is the large QoM value $(8.6 \mathrm{~mm} / \mathrm{s})$ of VJ when listening to music (\#18). Here she commented that she became very absorbed in the music and also noticed that she moved more during this particular recording. In future studies, we will investigate more systematically how various musical features may influence either the subjective experience or the QoM values of standing still.

\subsection{Influence of mental tasks}

One thing we were eager to investigate was whether the execution of different mental tasks, as opposed to the maintenance of focus upon only various physical aspects of the session, would influence the level of standstill. To test this, we carried out a series of sessions employing different types of mental strategies based on our previous experience: meditation exercises, counting numbers, and so on. Surprisingly, we found no correlation in QoM values between the two types of sessions.

This lack of a quantitative correlate between physical standstill and our subjective experience does not mean that we should avoid different types of mental tasks in an artistic setting. After all, the QoM value only reports the movement of the head marker; it does not reflect any other type of motion happening in the body. We all felt that the different mental tasks had an impact on the subjective experience of standing still, and we enjoyed many of these sessions the most. As such, if one's aim is to stand physically still for a long period of time, we would continue to advocate the use of one or more mental strategies to maintain focus.

Even though mental tasks did not appear to impact the QoM, we believe that it is possible to ascertain differences in the expressive character of the subject based on the mental strategy he or she employed during the standstill sessions. This particularly relates to the sense of 'being in the space', - for example, whether one's energy is transmitted outward or focused more inward. These are relevant artistic 
parameters that we now know can be utilised without necessarily influencing the measurable QoM.

Table 2 Some average statistics of the XYZ position values for all recordings

\begin{tabular}{|c|c|c|c|c|c|c|c|c|c|}
\hline & \multicolumn{3}{|c|}{$A R J$} & \multicolumn{3}{|c|}{$K A V B$} & \multicolumn{3}{|c|}{$V J$} \\
\hline & $X$ & $Y$ & $Z$ & $X$ & $Y$ & $Z$ & $X$ & Y & $Z$ \\
\hline Std.dev. & 6.0 & 11.4 & 1.4 & 6.4 & 13.6 & 1.4 & 7.6 & 10.8 & 2.0 \\
\hline Variance & 67.5 & 214.7 & 3.5 & 46.3 & 193.8 & 2.3 & 69.8 & 132.9 & 4.6 \\
\hline Skewness & -0.26 & -0.05 & 0.32 & 0.00 & -0.07 & 0.09 & -0.12 & 0.05 & -0.22 \\
\hline Kurtosis & -0.3 & -0.1 & -0.3 & 0.3 & 0.4 & 2.7 & -0.4 & -0.3 & 0.1 \\
\hline Slope & 0.016 & -0.019 & -0.005 & -0.005 & -0.015 & -0.002 & 0.023 & -0.030 & -0.004 \\
\hline
\end{tabular}

\subsection{Distribution of movement in space}

Now that we have presented the ways in which various types of physical and mental strategies did (or did not) influence the level of micromovement during our sessions, we will next examine the spatial distribution of these micromovements. As briefly mentioned in Section 4.3, an appraisal of the movement on the XY plane will indicate whether we were 'swaying' around an imagined centre column in the body. As the XY plots in Figure 5 reveal, more movement is happening along the $\mathrm{Y}$ axis (front-back) than on the $\mathrm{X}$ axis (left-right). In fact, as shown in Table 2, the average standard deviations of the $\mathrm{Y}$ axis are approximately double those of the $\mathrm{X}$ axis. We can attribute this to the fact that the feet stabilise sideways movement better than they do front to back movement. It would be interesting to see whether this finding might be used to track the orientation of a performer in space, by looking at the standard deviation of a single marker for a limited amount of time.

\subsection{Distribution of movement in time}

So far, our discussion has focused only on movement independent of time. Looking at the ways in which the values are distributed in time, we do not find any indication that there was a significant difference between the beginning and the end of the recordings. Originally, we expected that we would stand stiller at the beginning than at the end of a recording, either because of physical fatigue or boredom. But this was not the case: a visual inspection of all of the plots for all of the recordings shows that the stillest periods during the recordings seem to be distributed more or less evenly.

There is much less movement happening on the $\mathrm{Z}$ axis (up-down) than on the two other axes. We expected this, because people are generally more likely to move back and forth and sideways than up and down. One observation related to the $\mathrm{Z}$ axis, however, is that its average slope reveals a slight tendency to move downward (see Table 2). This could be an indication that we 'sink' a little when standing still over time, but the numbers are too small to point to a strong conclusion.

To test whether standing still for more than ten minutes would influence the results, we carried out one session in which we stood still for 15 minutes (\#17). While this certainly felt longer, the QoM data from this recording are not very different from those of the ten-minute recordings. We would assume that standing still for even longer 
periods of time would lead to fatigue and thereby higher QoM values, but this was not something that we were interested in pursuing further.

Figure $5 \mathrm{XY}$ movement patterns for the first ten standstill recordings of each of the three authors, running from top left corner in each set of the subplots

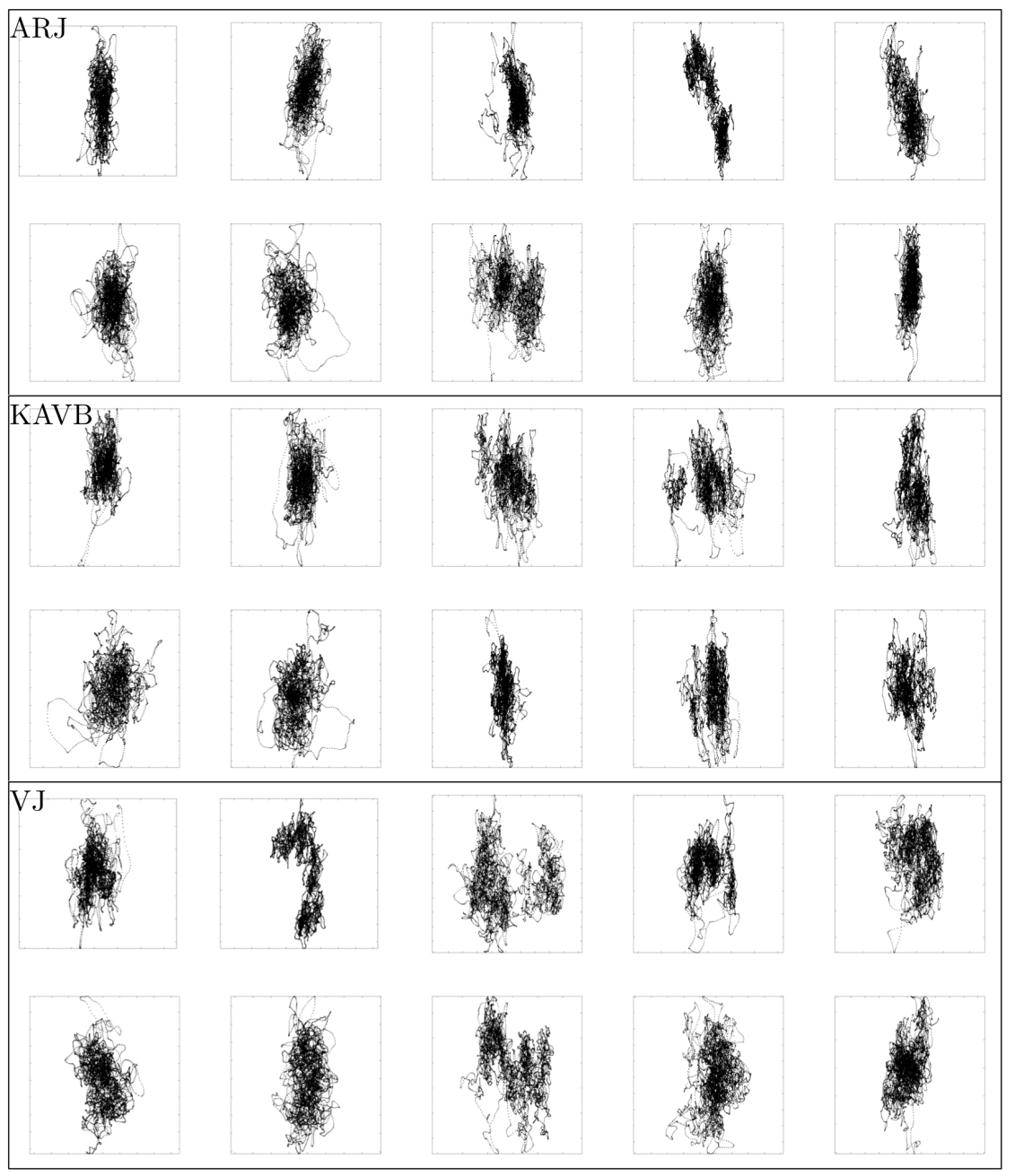

Note: The XY plots represent the left-right ( $\mathrm{X}$ axis) and front-back ( $\mathrm{Y}$ axis, face pointing upwards) movement of the head marker.

Looking more closely at the movement over time, we can identify (at least) three different temporal levels - micro, meso and macro - that in turn evoke the three main levels of the human memory (Snyder, 2000). At the temporal micro level, we find quasi-random movement happening on the scale of milliseconds. As suggested by Loram and Lakie (2002), these micromovements may be caused by the maintenance of the body's centre of mass a few centimetres in front of the ankle joint when one stand still, which makes the ankles work continuously to keep the body in balance. 
In our previous study (Jensenius and Bjerkestrand, 2012), we found clear periodic behaviour at the temporal meso level, at intervals of approximately five to ten seconds. These results derived from a marker placed on the neck, and we assumed this periodicity to be related to our breathing pattern. We have been unable to find a similarly clear periodicity in the present dataset. Using the mcperiod function in the MoCap Toolbox (Eerola et al., 2006), we have calculated the median values of all periodicities found for the magnitude of the position to be ARJ $=8 \mathrm{~s}, \mathrm{KAVB}=21 \mathrm{~s}$, and $\mathrm{VJ}=22 \mathrm{~s}$. However, the variances of these values are large and hence not easily generalisable. One reason for this large degree of variance is that the head is likely moving much more than the neck did in the previous study, which probably introduces more quasi-random movement, as reported by Loram and Lakie (2002), and hence more variation in the dataset.

At the temporal macro level, we found 'spikes' happening every two to three minutes in our previous study. These spikes can probably be explained by postural adjustments, and we see similar types of spikes in our new dataset, but, again, in a less structured manner than in the dataset of the neck marker.

\section{Conclusions}

Even though the dataset reported on in this paper is based on a limited number of people, a fairly small set of recordings, and many variables, we are able to draw several conclusions:

- It is not possible to stand absolutely still. Micromovements can be felt by the performer, can (to some extent) be seen by others, and can be tracked easily with a motion capture system. This holds promise for a systematic exploration and application of micromovements in artistic settings.

- The measurable level of standstill is in the range of 4-9 mm/s, and is remarkably similar and stable for all of us. This means that it is probably possible to use QoM measurements of performers for control purposes in an interactive system.

- The best strategy for achieving the lowest possible QoM is to stand with the feet at the width of the shoulders, with knees locked, and with eyes open.

- Different mental tasks do not seem to have any particular effect on the measurable level of standstill. They do have a major impact on the performer's experience of standing still, however, and we further believe that evidence of the mental strategy can also be seen by an observer.

- Breathing seems to be the most important factor influencing micro-movements at the temporal meso level, and postural adjustment at the temporal macro level. Findings from the current study are not as clear as the results obtained in our previous study (Jensenius and Bjerkestrand, 2012), perhaps because we used a (more unstable) head marker instead of a neck marker.

- Data obtained from a marker placed on the head are 'noisier' than data obtained from a marker placed on the neck or even on the lower back. Though this constitutes a drawback of sorts, we like to think of this 'noise' as a good source material for future artistic exploration. Our artistic motivation is focused on revealing the complexity of human micromovements, and on using this 
complexity to create dance and music. As such, we prefer to have a noisier (that is, richer) starting point.

Asides from these findings, we believe that the most important result of the study has been the team's development of a heightened sensitivity about and awareness of micromovements. This, we believe, will give us a new artistic platform with which to work. In the future, we will:

- conduct more standstill studies of ourselves, in the interests of obtaining more baseline data and further developing our shared sensitivity to our own micromovements

- $\quad$ use the knowledge we gain to guide other musicians/dancers as to how to achieve a similar awareness of their own micromovements

- $\quad$ explore different types of micromovement exercises, particularly working back and forth between voluntary and involuntary micromovements

- $\quad$ explore different sonification strategies for creating sound from micro-movements interactively

- develop a series of smaller artistic showcases that test out various micro-movement/microsound techniques in performance

- develop a full-scale stage performance based on all of the above.

\section{Acknowledgements}

The project has been supported by the Arts Council Norway, Norwegian Research Council, University of Oslo, and Norwegian Academy of Music.

\section{References}

Barlow, W. (1975) Alexander-princippet, Borgen forlag, Copenhagen.

Cage, J. (1961) Silence: Lectures and Writings, Wesleyan University Press, Middletown, CT.

Collins, J. and De Luca, C. (1994) 'Random walking during quiet standing', Physical Review Letters, Vol. 73, No. 5, p.764-767.

Eerola, T. et al. (2006) 'An investigation of pre-schoolers' corporeal synchronization with music', in Proceedings of the International Conference on Music Perception and Cognition, Bologna, pp.472-476.

Ekman, P. and Friesen, W.V. (1969) 'The repertoire of nonverbal behavioral categories', Semiotica, Vol. 1, No. 1, pp.49-98.

Feldenkrais, M. (1972) Awareness Through Movement: Health Exercises for Personal Growth, Harper Row, New York.

Jacobsson, S. and Bjerkestrand, K.A.V. (2005) 10:50-11:15, (video) [online] http://youtu.be/y3GECC2 4xY (accessed 24 August 2012).

Jensenius, A.R. and Bjerkestrand, K.A.V. (2012) 'Exploring micromovements with motion capture and sonification', in A.L. Brooks (Ed.): Arts and Technology, Second International Conference, ArtsIT 2011, pp.100-107, Esbjerg, Denmark, December 7-8, 2011, Revised selected papers, Vol. 101 of LNICST, Springer, Berlin. 
Jensenius, A.R. and Johnson, V. (2010) 'A video based analysis system for realtime control of concatenative sound synthesis and spatialisation', in S. Yildirim and A. Kofod-Petersen (Eds.): Proceedings of Norwegian Artificial Intelligence Symposium, pp.85-88, Trondheim, Tapir Akademisk Forlag.

Jensenius, A.R. et al. (2010) 'Musical Gestures: concepts and methods in research', in R.I. Godøy and M. Leman (Eds.): Musical Gestures: Sound, Movement, and Meaning, pp.12-35, Routledge, New York.

Jensenius, A.R. et al. (2012) 'A study of the noise-level in two infrared marker-based motion capture systems', in Proceedings of the Sound and Music Computing Conference, Copenhagen, pp.258-263.

Johnson, D. (1995) Bone, Breath and Gesture: Practices of Embodiment, North Atlantic Books, Berkeley, CA.

Klein, G. (2007) Farewell to the Internal Clock: A Contribution in the Field of Chronobiology, Springer, New York, NY.

Kozel, S. (2011) 'Micro-mocap', in Proceedings of the International Symposium on Electronic Art, Istanbul.

Kurihara, N. (2000) 'Hijikata Tatsumi: the words of butoh', The Drama Review, Vol. 44, No. 1, pp.10-28.

Laeng, B. and Teodorescu, D. (2002) 'Eye scanpaths during visual imagery reenact those of perception of the same visual scene', Cognitive Science, Vol. 26, No. 2, pp.207-231.

Loram, I. and Lakie, M. (2002) 'Direct measurement of human ankle stiffness during quiet standing: the intrinsic mechanical stiffness is insufficient for stability', The Journal of Physiology, Vol. 545, No. 3, pp.1041-1053.

Martinez-Conde, S. and Macknik, S.L. (2007) 'Windows on the mind', Scientific American, Vol. 297, No. 2, pp.56-63.

Mulholland, T. (1995) 'Human EEG, behavioral stillness and biofeedback', International Journal of Psychophysiology, Vol. 19, No. 3, pp.263-279.

Saltonstall, E. (1988) Kinetic Awareness, Discovering Your Bodymind, Pub Center Cultural Resources, New York, NY.

Skogstad, S.A. et al. (2010) 'Using IR optical marker based motion capture for exploring musical interaction', in Proceedings of the International Conference on New Interfaces for Musical Expression, pp.407-410, Sydney.

Snyder, B. (2000) Music and Memory: An Introduction, The MIT Press, Cambridge, MA.

Toiviainen, P. and Burger, B. (2010) MoCap Toolbox Manual, University of Jyväskylä, Jyväskylä.

Winter, D. (1995) 'Human balance and posture control during standing and walking', Gait and Posture, Vol. 3, No. 4, pp.193-214.

Winter, D. et al. (1998) 'Stiffness control of balance in quiet standing', Journal of Neurophysiology, Vol. 80, No. 3, p.1211. 